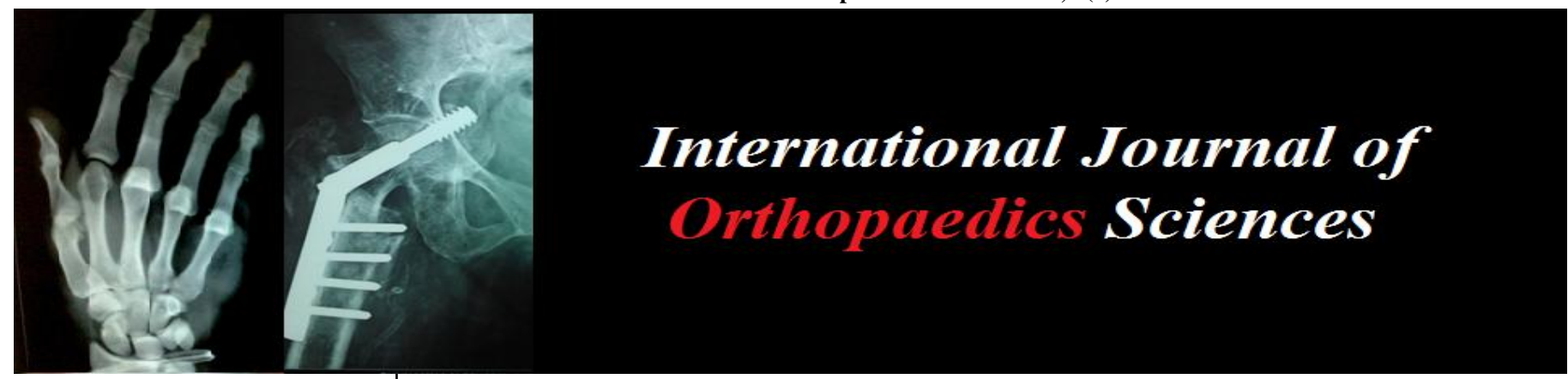

ISSN: $2395-1958$

IJOS 2018; 4(1): 115-119

(C) 2018 IJOS

www.orthopaper.com

Received: 20-11-2017

Accepted: 21-12-2017

Dr. Rajat Tak

Senior Resident at Govt Medical College Kota, Rajasthan, India

Dr. Sachin Joshi

Assistant Professor Govt Medical College Kota, Rajasthan, India
Correspondence

Dr. Rajat Tak

Senior Resident at Govt Medical

College Kota, Rajasthan, India

\section{Outcome analysis of hybrid fixation technique (radius nailing and ulna plating) in closed proximal radius and ulna fractures in adults}

\author{
Dr. Rajat Tak and Dr. Sachin Joshi
}

DOI: https://doi.org/10.22271/ortho.2018.v4.i1b.20

\begin{abstract}
Background: The aim of the study was to evaluate results of hybrid fixation technique (radius nailing and ulna plating) in closed proximal radius and ulna fractures in adults. The hypothesis behind hybrid fixation is to provide rigid fixation and restoration of forearm length, by ulna plating and large diameter square nail in radius gives rotational stability without any posterior interosseous nerve palsy in proximal radius and ulna fractures. Closed nailing of proximal radius avoid posterior interosseous nerve palsy which has high probability in open surgical approach.

Materials and method: We prospectively evaluated 25 patients with closed proximal radius and ulna fractures. 20 males and 5 females with mean age of 30.7 years underwent closed reduction and intramedullary nail fixation in radius and open reduction internal fixation in ulna with plating. The fractures were classified according to the AO/OTA system. The average follow up was 1 year (range 6 months -18 months).

Results: The average time to union was 12.77 weeks (10-14 weeks). Union was achieved in all 25 patients in both radius and ulna. Using the Grace and Eversmann rating system7 patients were excellent, 16 good, 1 acceptable and 1 unacceptable results. Using Andersons scale 23 patients had an excellent, 2 unsatisfactory, 0 failure. None of the patients had intraoperative as well as postoperative complications and no posterior interosseous nerve palsy occurred in any of case.

Conclusion: Closed reduction internal fixation with use of Hybrid fixation modality in closed proximal radius and ulna fractures has good results. Rigid fixation by ulna plating and rotational stability in radius by large diameter square nail provides almost the same construct as with dual plating with minimal invasive approach. Complication rates are lower as compared to plate osteosynthesis especially with similar union rates in terms of posterior interosseous nerve palsy.
\end{abstract}

Keywords: Closed proximal half radius-ulna fractures, hybrid forearm fixation technique, square nail, closed intramedullary radius nailing, ulna plating, posterior interosseous nerve palsy

\section{Introduction}

Although forearm fractures are relatively common, the incidence of fracture is reported to be approximately 1 to 10 per 10,000 persons per year. Males are affected more than females. Mean age group ranges from 24-37 years.

The usual treatment preferred in adults is operative. There are various modes of operative fixations available, the choice of which rests with the treating surgeon. However there are always fair chances of posterior interosseous nerve injury in proximal radius plating. The reported incidence of posterior interosseous nerve palsy around $10 \%$ of all patients with proximal radius fractures treated with plating due to its sub muscular branches, which is somehow not acceptable if we have any alternative to save this.

Plate osteosynthesis is the most commonly used technique for the treatment of forearm fractures in adults. The use of intramedullary devices to stabilize fractures is not new, Intramedullary nailing usually used in open fractures in adults. But combination of radius nailing and ulna plating is new concept in orthopaedics trauma methodology in closed fractures.

Intramedullary nailing has its own sets of advantages and disadvantages. The infection rates are significantly decreased, as it is a closed procedure without periosteal stripping. 
There is no need of dissection in radius make the procedure almost free of any nerve injury while absolute rigid fixation provided by plating in ulna gives forearm rotational stability. It also has lower rates of re-fracture after implant removal, if needed.

The aim of this study was to assess, in adults, the results of closed radius nailing and ulna plating to evaluate the anatomical and functional acceptance of the procedure.

\section{Materials and Methods}

The study was conducted in University Teaching Hospital, I.M.S., B.H.U, Varanasi after obtaining clearance from the ethical committee. All study participants given written informed consent for participation in this study. The study was conducted from July 2014 to June2016 on patients admitted from the emergency or OPD of orthopaedics department of the hospital.

We evaluated 25 patients (20 males and 5 females) who met the inclusion and exclusion criteria.

\section{Inclusion Criteria}

A) Skeletally mature both- men and women.

B) Proximal half of shaft fractures of radius and ulna fractures.

C) All closed fractures without neurovascular deficit.

D) Those who will give consent and willing to come for regular follow up.

\section{Exclusion Criteria}

a) Skeletally immaturity. ( $<18$ years)

b) Single bone fractures,

c) Presence of neurovascular deficit.

d) Monteggia fractures (Except Type 4), pathological fractures, distal radio ulnar joint instability, bilateral fractures and bone loss.

e) Open fractures.

f) Old maluited fractures of radius/ulna.

All study participants were followed up for a minimum of one year and maximum of one year and half years.

\section{Implant Design}

Stainless steel square nails/ Titanium elastic nails were used for all patients for radius nailing and $3.5 \mathrm{~mm}$ limited contact dynamic compressions plate / locking compression plate for ulna. Nail diameters were $2.0 \mathrm{~mm}, 2.5 \mathrm{~mm}, 3.0 \mathrm{~mm}$ with nail lengths from $16 \mathrm{cms}$ to $25 \mathrm{~cm}$. The radius nail has a bevelled edge this adds to the flexibility and ease of negotiation along the radial bow. Using large diameter tightly fitted square nail provides rotational stability to radius.

\section{Preoperative planning}

Radiographs were evaluated for each patient for type and location of fractures. The size of the nails was estimated on the normal limb radiograph. The radius nail was measured from the Lister's tubercle to the lateral epicondyle minus $3 \mathrm{~cm}$.

\section{Operative procedure}

Most of the times ulnar fixation was done primarily there by providing a more stable forearm for radius nailing.

\section{Technique for radius nailing}

* Under general or regional (Axillary block) anaesthesia, the patient is positioned supine.

* Radial traction is needed to reduce fragments, though after ulnar fixation it usually align itself.
* A $2 \mathrm{~cm}$ incision is made just ulnar to the Lister's tubercle on the dorsal surface and soft tissue was divided.

* The 3rd extensor compartment is opened. The tendon of the extensor pollicislongus is identified and retracted.

* Nail is inserted up to proximal border of the bicipital tuberosity of the radius.

In none of the cases open reduction for radius was required. And open reduction internal fixation for ulna was done using 3.5 LCDCP.

\section{Post-operative}

Patients were immobilized with an above elbow splint for 2-3 weeks and asked to perform active finger movements. Patients were discharged on the 3rd to 4th day post-op. Patients were evaluated monthly and radio graphically at 4weekly intervals till union and then at 3-monthly intervals. Results were assessed on the basis of the time to union, functional recovery and complications.

Union was defined as the presence of bridging bone or trabeculae spanning the fracture site. All patients were prescribed physiotherapy for range of motion and strengthening exercises.

At the last assessment, the degree of forearm rotation was measured with a goniometer. Functional outcome was calculated using the system described by Grace and Eversman and Andersons scale, Mayo elbow performance score.

\section{Mayo elbow performance score}

\begin{tabular}{|c|c|}
\hline Criteria & Points \\
\hline \multicolumn{2}{|l|}{ Pain (45 points) } \\
\hline None & 45 \\
\hline Mild & 30 \\
\hline Moderate & 15 \\
\hline Severe & 0 \\
\hline \multicolumn{2}{|l|}{ ROM (20 points) } \\
\hline 100 degrees & 20 \\
\hline 50-100 degrees & 15 \\
\hline$<50$ degree & 5 \\
\hline \multicolumn{2}{|l|}{ Stability (10 points) } \\
\hline Stable & 10 \\
\hline Moderate instability & 5 \\
\hline Gross instability & 0 \\
\hline \multicolumn{2}{|l|}{ Daily function (25 points) } \\
\hline Combing hair & 5 \\
\hline Feeding oneself & 5 \\
\hline Hygiene & 5 \\
\hline Putting on shirt & 5 \\
\hline Putting on shoes & 5 \\
\hline
\end{tabular}

Total score 100 points

$>90$ points $=$ excellent, 75 to 89 points $=$ good, 60 to 74 points $=$ fair, and less than 60 points $=$ poor

Stable = No apparent varus-valgus laxity clinically, moderate instability = less than 10 degrees of varus-valgus laxity, and gross instability $=$ at least 10 degrees of varus-valgus laxity.

\section{Anderson devised an outcome scale based on final range of motion}

1. Excellent rating: patients with $<10$ degree loss of flexion -extension and $<25 \%$ loss of pronation and supination.

2. Unsatisfactory :> 30 degree loss of flexion -extension and $>50 \%$ loss of pronation and supination.

3. Failure: defined as non union with or without loss of motion. 
Grace and Eversmann devised a similar outcome tool for range of motion and healing

1. Excellent result: Healed fractures with at least $90 \%$ of normal rotation determined by uninjured contralateral side.

2. Good result: healed fracture with $80 \%-89 \%$ of normal rotation.
3. Acceptable result: Healed fracture with $60-79 \%$ of normal rotation.

4. Unacceptable result: Nonunion or fractures with $<60 \%$ of normal forearm rotation.

\section{Summary of patients}

\begin{tabular}{|c|c|}
\hline Variables & \\
\hline No. of patients & 25 \\
\hline Mean age (years) & 30.7 \\
\hline Sex (Male : Female) & $4: 1$ \\
\hline Fracture site (Right : Left) & $11: 14$ \\
\hline Injury mechanism & \\
\hline Traffic accident & 13 \\
\hline Work injury & 3 \\
\hline Fall down & 5 \\
\hline Sports injury & 4 \\
\hline Follow up (Mean, weeks) & 12 \\
\hline
\end{tabular}
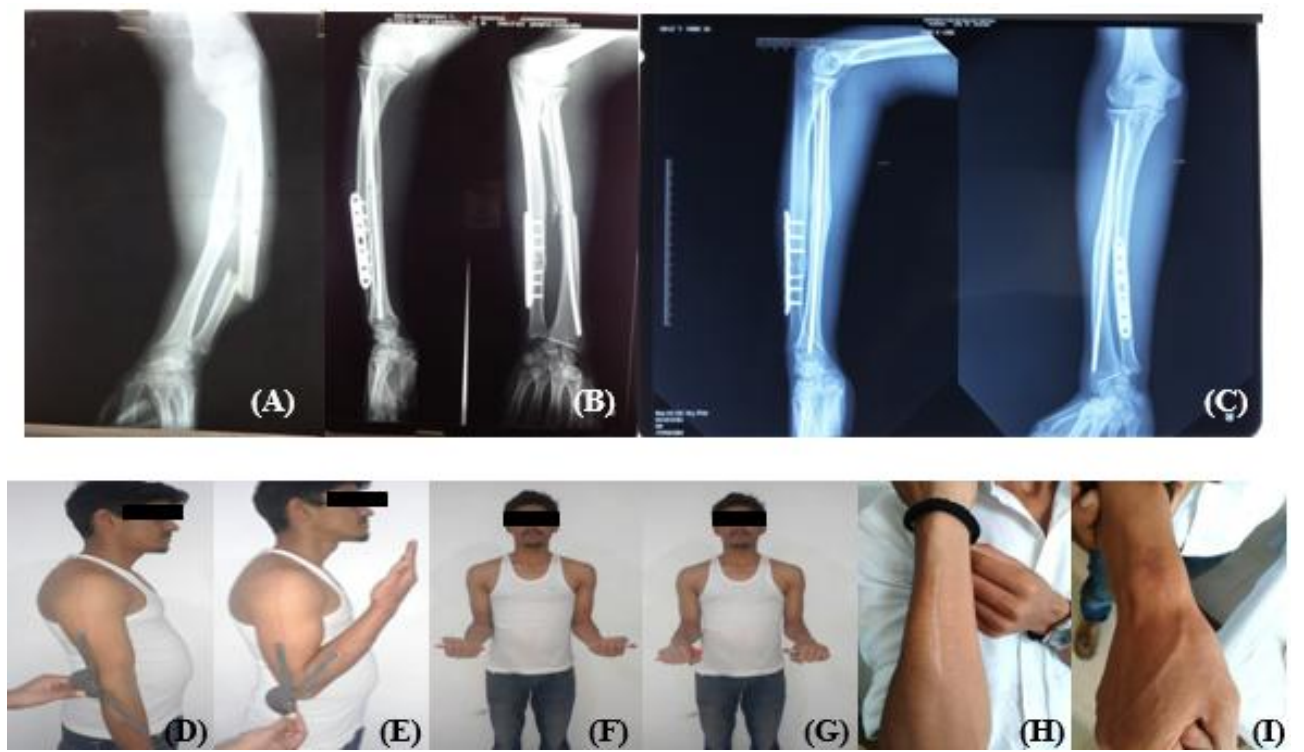

Fig 1: Case 1: 21/m alleged h/o road traffic accident, right side both bone forearm fracture. (A) Pre-op X-ray, (B) Immediate post-op X-ray, (C) Follow up at 4 months (D, E) Extension and Flexion at 4 months (F, G) supination \& pronation (H, I) Scar - Ulna plating, radius nailing.
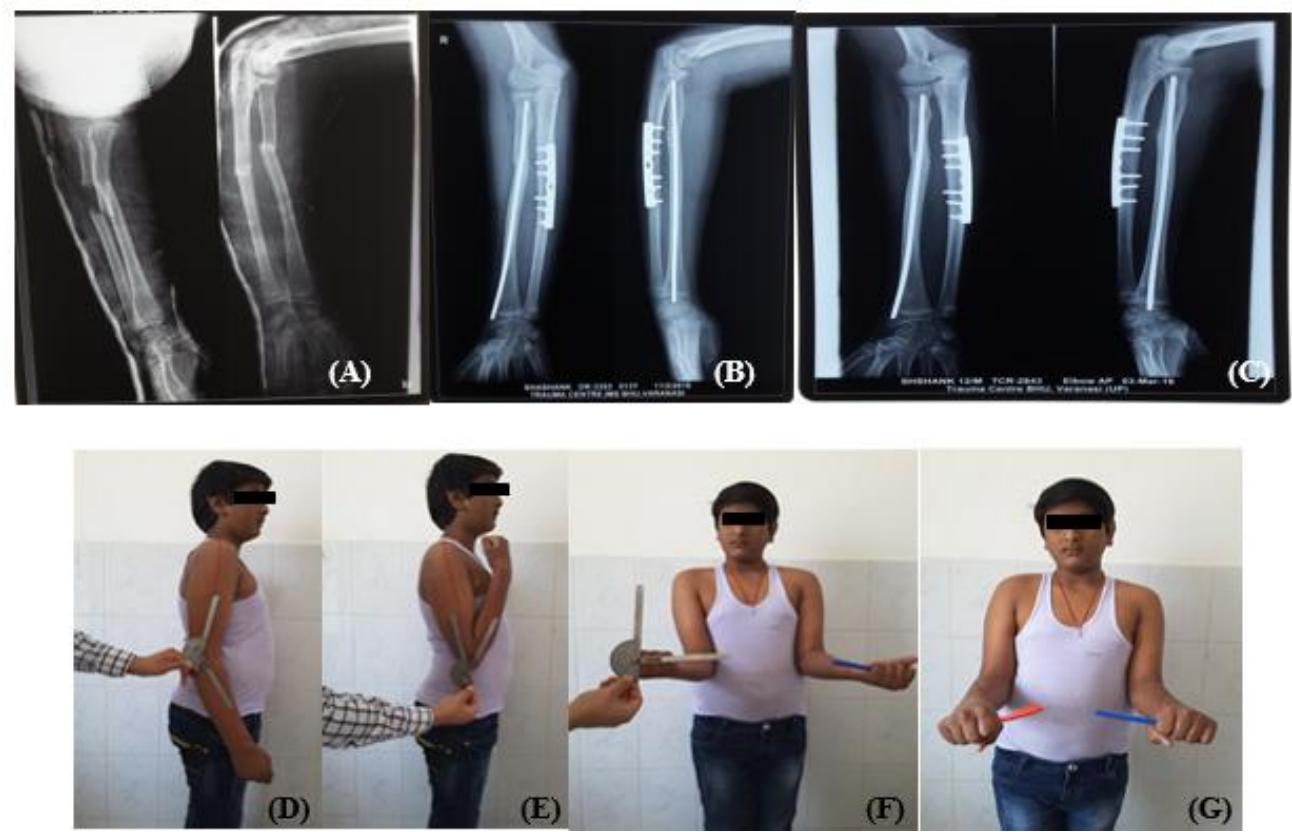

Fig 2: Case 2: 17 y/m, right side fracture, h/o RTA. (A) Pre-op X-ray, (B) Immediate post-op X-ray, (C) Followup at 3 months (D, E) Extension and Flexion at 3 months $(F, G)$ supination \& pronation. 
Results

\begin{tabular}{|c|c|}
\hline Variables & \\
\hline \multicolumn{2}{|l|}{ Grace and Eversman } \\
\hline Excellent & 7 \\
\hline Good & 16 \\
\hline Acceptable & 1 \\
\hline Unacceptable & 1 \\
\hline \multicolumn{2}{|l|}{ Andersons scale } \\
\hline Excellent & 23 \\
\hline Unsatisfactory & 2 \\
\hline Failure & 0 \\
\hline \multicolumn{2}{|l|}{ Mayo Elbow performance } \\
\hline$>90$ points & 21 \\
\hline $75-89$ points & 4 \\
\hline $60-74$ points & 0 \\
\hline$<60$ points & 0 \\
\hline Union time weeks, Range of motion, Supination & 12.77wks \\
\hline $76-80^{0}$ & 3 \\
\hline $71-75^{0}$ & 6 \\
\hline $66-70^{0}$ & 13 \\
\hline $61-65^{0}$ & 2 \\
\hline$\leq 60^{\circ}$ & 1 \\
\hline \multicolumn{2}{|l|}{ Pronation } \\
\hline $71-75^{0}$ & 2 \\
\hline $66-70^{0}$ & 10 \\
\hline $61-65^{0}$ & 10 \\
\hline$\leq 60^{\circ}$ & 3 \\
\hline \multicolumn{2}{|l|}{ Flexion } \\
\hline $141-145^{0}$ & 6 \\
\hline $136-140^{0}$ & 11 \\
\hline $131-135^{0}$ & 6 \\
\hline$\leq 130^{\circ}$ & 2 \\
\hline \multicolumn{2}{|l|}{ Extension } \\
\hline$>30^{\circ}$ & 1 \\
\hline $21-30^{0}$ & 8 \\
\hline $11-20^{0}$ & 12 \\
\hline $00-10^{0}$ & 4 \\
\hline
\end{tabular}

The patients were followed up for a minimum of 6 months and maximum of one and half years postoperatively. The mean age of study participants was 30.7 years. The right limb was fractured in 11 subjects and the left limb was fractured in 14 subjects. The mode of injury was road traffic accidents $52 \%$, falls $20 \%$, Sports injury $16 \%$ work injury $12 \%$.

The average operative time was 55 minutes, and average fluoroscopy unit exposure was $10 \mathrm{~min}$. No intraoperative complication occurred nor was any radius nailing converted to some other method of fixation. The average hospital stay was 4 days (range, 2- 5 days).

The average time to union was 12.77 weeks (range, 10-14 weeks). Forearm brace with elbow hinge support was maintained for a mean of 3 weeks. Radius and ulna unites in all cases. There was $>30^{\circ}$ loss of flexion or extension in 2 patients as compared to the other arm. Pronation and supination was restricted to $>50 \%$ in these 2 patients.

Using the rating system of Grace and Eversmann, 7 patients had an excellent, 16 good, 1 acceptable, 1 unacceptable results.

Using Andersons scale 23 patients had an excellent, 2 unsatisfactory, 0 failure results. None of the patients had intraoperative as well as postoperative complications and no neurological deficit (posterior interosseous nerve palsy).

\section{Discussion}

Plate fixation has been the gold standard for fixation of forearm bones. To achieve good functional recovery anatomical reduction is required for which open reduction internal fixation is often needed but few riders are there for opting radius nailing in proximal fractures due to high incidence of posterior interosseous nerve palsy.

We hypothesised intramedullary nailing is good option to be performed in closed proximal radius fractures keeping in view that there are high frequency of intraoperative nerve palsy (PIN) reported in proximal radius fractures. The reported incidence of posterior interosseous nerve palsy is $7-10 \%$ of all patients with proximal radius fractures treated with plating ${ }^{[3]}$. Plating is regarded safe modality, but many times a straight plate unable to restore radial bow in proximal radius fractures because of its anatomy [11]. At proximal-mid one third junction radius becomes circular to triangular. The concept behind hybrid fixation is to provide rigid fixation along with restoration of forearm length by ulna plating and a large diameter square nail in radius provides rotational stability without any posterior interosseous nerve palsy in proximal radius fractures.

Closed nailing has many advantages - low incidence of infection, small scars \& good cosmetic results, less blood loss, relatively short operating time with minimal surgical trauma, less expenditure, less chances of compartment syndrome, less need of analgesics, less postoperative complications, no neurological deficit, no tourniquet palsy.

In our experience, the main complications during surgery were due to improper nail size. Another important advantage of intramedullary implants is their stress-sharing behaviour, which facilitates secondary periosteal callus formation.

The results of old methods of intramedullary nailing (K-wire, rush nail, Steinman pins) have high rates of non-union $20 \%$ $[11,16,17]$. But with the introduction of square design to improve rotational stability, which dramatically changed the non-union rates. Street et al reported $93 \%$ union rates and $84 \%$ good functional results with the use of square nails ${ }^{[10]}$. Intramedullary nailing creates a strong construct that is able to resist bending loads but less effective in resisting rotational loads. However square nail provides good rotational stability and in combination with rigid ulna plating, the overall forearm construct is biomechanically strong.

In one study of plate osteosynthesisvs nailing - plate osteosynthesis group radius showed union in $93.2 \%$ and ulna in $86.8 \%$, and in closed nailing group both radius and ulna resulted in $100 \%$ union rate ${ }^{[5]}$.

We achieved union in all cases in both radius and ulnaand good functional outcome in 23 out of 25 patients (92\%).

\section{Conclusion}

Closed reduction internal fixation with use of hybrid fixation modalityin closed proximal radius and ulna fractures has good results. Rigid fixation by ulna plating and rotational stability in radius by large diameter square nail provides almost the same contruct as with dual plating with minimal invasive approach. Complication rates are lower as compared to plate osteosynthesis. Intramedullary nailing can be considered in repair of closed forearm fractures keeping in view its complications rates, cost, acceptable and good functional results.

Ethical standard: All the 25 study participants gave the informed consent prior to being included in the study. The procedure involving human participants were in accordance with the 'Ethical Guidelines for Biomedical Research on Human Subjects' laid down by the Indian Council of Medical Research in the year 2000. 
This study was cleared from ethical committee meeting on 30.12.2015, EC registration no: ECR/526/Inst/UP/2014 Dt.31.1.14.

\section{Conflict of interest: None}

\section{References}

1. Shaft fractures of both bones: The outcomes of surgical treatment with plating only and combine plating and intramedullary nailing. Clinics in orthopaedic surgery : Sang bum kim, MD Youn moo heo, MD, jinwoong Yi MD, jung bun lee, MD ByoungGu Lim MD.

2. Nadeem Lil A, Damandeep Makkar S, Adatia Aleem A. Results of closed intramedullary nailing using Talwarkar square nail in adults forearm fractures. Malaysian Orthopedic Journal.

3. Moerman J, Leneart A, Deconinck D, Haeck L, Verbeke $S$, Uyttendaele D. Intramedullary fixation of forearm fractures in adults. ActaOrthop Belg. 1996; 62(1):3440. [PubMed]

4. Wasudeo Gadegone, Yogesh Salphale S, Vijayanand Lokhande. Screw elastic intramedullary nail for the management of adult forearm fracture - Indian journal of orthopaedics. 2012; 46(1):65-70.

5. Suneet Tendon, Mohammad Zuber, Radheyshyamdhiman S. Gaur - Results of closed intramedullary nailing vs plate osteosynthesis in diaphyseal fractures of both bones forearm in adults.

6. Rao MR, Kader E, Sujith SV, Thomas V. Nail-plate combination in management of fracture both bone forearm. J Bone Joint Surg (Br). 2002; 84(B):252-253.

7. Rao R. A prospective study of pediatric forearm bone fractures treated with closed intramedullary square nailing. J. Orthopaedics. 2009; 6(1):12-12.

8. Lee YH, Lee SK, Chung MS, Baek GH, Gong HS, Kim $\mathrm{KH}$. Interlocking contoured intramedullary nail fixation for selected diaphyseal fractures of the forearm in adults. J Bone Joint Surg Am. 2008; 90(9):18911898. [PubMed]

9. Barry M, Paterson JMH. Flexible intramedullary nails for fractures in children. J Bone Joint Surg Br. 2004; 86:947953. [PubMed]

10. Street DM. Intramedullary forearm nailing. Clin Orthop Relat Res. 1986; 212:219-230. [PubMed]

11. Sage FP. Medullary fixation of fractures of the forearm.A study of the medullary canal of the radius and a report of fifty fractures of the radius treated with a prebent triangular nail. J Bone Joint Surg Am. 1959; 41:1489516. [PubMed]

12. Talwalkar AK, Talwalkar CA. internal fixation of fractures of radius and ulna in adults with Talwalkar intramedullary nails. Indian J Orthop. 1967; 1(1):26-30.

13. Bansal $\mathrm{H}$. intermedullary fixation of forearm fractures with new locked nail. Indian J Orthop. 2011; 45(5):410416. [PMC free article] [PubMed]

14. Grace TG, Eversmann WW Jr. Forearm fractures: treatment by rigid fixation with early motion. J Bone Joint Surg Am. 1980; 62:433-438. [PubMed]

15. Dowrick AS, Gabbe BJ, Williamson OD, Cameron AP. Does the disability of the arm, shoulder and hand (DASH) scoring system only measure disability due to injuries to the upper limb. J Bone Joint Surg Br. 2006; 88:524-527. [PubMed]

16. Smith H, Sage FP. Medullary fixation of forearm fractures. J Bone Joint Surg Am. 1959; 39:91-8.
[PubMed]

17. Crenshaw AH, Zinar DM, Pickering RM. Intramedullary nailing of forearm fractures Instr Course Lect. 2002; 51:279-89. [PubMed]

18. Droll KP, Perna P, Potter J, Harniman E, Schemitsch EH, McKee MD. Outcomes Following Plate Fixation of Fractures of Both Bones of the Forearm in Adults. J Bone Joint Surg (Am). 2007; 89(12):2619-2624. [PubMed]

19. Moed BR, Kellam JF, Foster JR, Tile M, Hansen ST Jr. Immediate internal fixation of open fractures of the diaphysis of the forearm. J Bone Joint Surg Am. 1986; 68:1008-1017. [PubMed]

20. Moda SK, Chadha NS, Kochhar A, Aggarwal A, Garg A. management of forearm fractures by open reduction and fixation with talwalkar square nails. Indian J Orthop. 1988; 22(1):22-28. 